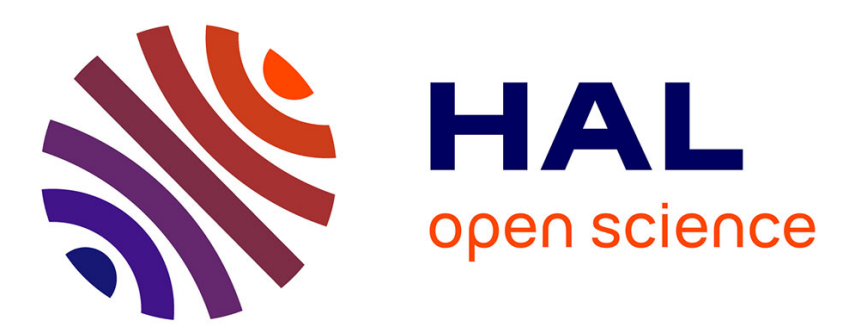

\title{
Surface thermoelastic deformations caused by a laser
}

\author{
N. Tankovsky, D. Ivanov, J. Burov
}

\section{To cite this version:}

N. Tankovsky, D. Ivanov, J. Burov. Surface thermoelastic deformations caused by a laser. Revue de Physique Appliquée, 1984, 19 (8), pp.631-634. 10.1051/rphysap:01984001908063100 . jpa-00245231

\section{HAL Id: jpa-00245231 https://hal.science/jpa-00245231}

Submitted on 1 Jan 1984

HAL is a multi-disciplinary open access archive for the deposit and dissemination of scientific research documents, whether they are published or not. The documents may come from teaching and research institutions in France or abroad, or from public or private research centers.
L'archive ouverte pluridisciplinaire HAL, est destinée au dépôt et à la diffusion de documents scientifiques de niveau recherche, publiés ou non, émanant des établissements d'enseignement et de recherche français ou étrangers, des laboratoires publics ou privés. 


\title{
Surface thermoelastic deformations caused by a laser
}

\author{
N. Tankovsky, D. Ivanov and J. Burov \\ Department of Solid State Physics, Faculty of Physics, Sofia University, 5 A. Ivanov Blvd., Sofia 1126, Bulgaria
}

(Reçu le 2 mars 1984, révisé le 9 mai, accepté le 30 mai 1984)

\begin{abstract}
Résumé. - Une méthode est proposée pour déterminer expérimentalement avec précision la topographie des déformations thermoélastiques de surface, provoquées par un faisceau continu laser, focalisé en un point. Une expression théorique approchée des déformations de surface des matériaux anisotropes a été obtenue. Des coupes différentes de quartz et de verre ont été examinées.
\end{abstract}

\begin{abstract}
A method is suggested for an accurate experimental measurement of the topography of the surface thermoelastic deformations in solids, induced by a point focused CW laser beam. An approximate theory for the surface deformation of anisotropic materials is obtained. Different cuts of quartz and glass samples have been examined.
\end{abstract}

\section{Introduction.}

In recent years the study of the thermoelastic surface deformations, induced by a laser has become of interest in connection with two main fields of application - the laser generation of surface acoustic waves in solids and the photodisplacement microscopy [1-3]. The thermal excitation of surface acoustic waves is based on the creation of periodic surface deformations by a modulated laser whose light energy is absorbed at the surface of a solid body. It is clear that by choosing appropriate cuts of the anisotropic solid body it is possible to achieve optimal surface acoustic wave excitation. In order to solve this problem it is necessary to study the topography of the surface deformations around the heating source. These deformations depend on the thermal source distribution at the surface and the thermoelastic characteristics of the material beneath the surface. In cases when the theoretical calculations are very complicated the experimental methods provide the only means to treat the problem.

In this paper a method is suggested for both theoretical and experimental study of the surface deformations induced by a steady, point-laser heat source. The information obtained gives the possibility of solving problems concerning the optimal efficiency of surface acoustic wave thermal generation, the spatial temperature distribution around a surface thermal source of arbitrary shape, the photodisplacement microscopy, etc.

\section{Experiment.}

An optical interferometric method, based on Newton fringes was used. A broad and uniform laser beam shaped by a collimator passes through a lens and illuminates the surface to be examined. Newton fringes are formed as a result of multireflection and interference of the light at different points of the laser beam cross section. The point heating source must be in the centre of the Newton fringes to preserve the symmetry of the interference patterns. After the surface deformation is created by the heating laser, the optical paths of the probing laser beam are changed in accordance with the deformation shape, leading to changes in the interference pattern. Photograph pictures are taken before and after the heating. An arbitrary point must be precisely identified on both pictures and the difference in the number of fringes from the centre to the same point gives us the amplitude of the deformation in that point, measured in light half-wavelengths. Thus a complete information about the topography of the surface deformation can be obtained.

The experimental set-up is shown schematically in figure 1. The heating $0.8 \mathrm{~W}$ argon laser is focused in a spot $500 \mu \mathrm{m}$ in diameter on the surface of the sample, where for a better absorption a droplet of indian ink is applied. The probing He-Ne laser beam passes through a collimator and a diaphragm, which defines the size of the surface spot illuminated. Usually a diameter of 1.5 to $2 \mathrm{~cm}$ is enough to illuminate the surface defor- 


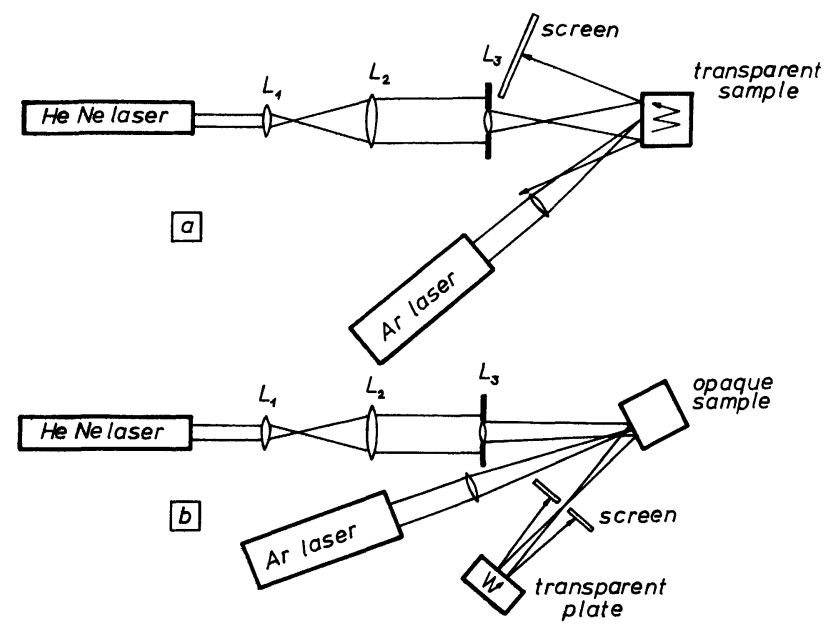

Fig. 1. - Experimental set-up. a) Case of a transparent sample. b) Case of an opaque sample.

mation. If the sample is transparent it must have two parallel polished faces so that interference through multireflection of beams becomes possible (Fig. 1a). If the sample is opaque only one face is to be polished to reflect the probing laser beam. Multireflection of beams is provided by a transparent optical flat plate placed as shown in figure $1 \mathrm{~b}$. One must notice that the transparent sample allows a higher sensitivity than the opaque one because the phase shift is $n$ times greater in the first case, $n$ being the sample index of refraction.

\section{Theory.}

Our theoretical analysis will concern the steady state thermoelastic surface deformations and hence all magnitudes will be functions of the three space coordinates and will be independent of time. For most of the anisotropic crystals the heat flow and thermal expansion tensors are symmetrical and can be diagonalized. So we can write the stationary heat flow equation as follows :

$$
K_{1} \frac{\partial^{2} T}{\partial x_{1}^{2}}+K_{2} \frac{\partial^{2} T}{\partial x_{2}^{2}}+K_{3} \frac{\partial^{2} T}{\partial x_{3}^{2}}=0 .
$$

Where $K_{1}, K_{2}, K_{3}$ are the main heat flow coefficients and $T\left(x_{1}, x_{2}, x_{3}\right)$ is the space temperature distribution. The solution of (1) for a point heat source based on the surface $x_{i}=0$ with coordinates $(0,0,0)$ and boundary conditions $T(0,0,0)=\infty$ and $T\left(x_{i}=0\right.$, $\left.x_{l}, x_{j}\right)=0, i \neq l \neq j$ is given by the formula :

$$
\begin{aligned}
& T\left(x_{1}, x_{2}, x_{3}\right)=\left(x_{i} / K_{i}\right)\left[\left(x_{1}^{2} / K_{1}\right)+\right. \\
& \left.+\left(x_{2}^{2} / K_{2}\right)+\left(x_{3}^{2} / K_{3}\right)\right]^{-3 / 2}\left(K_{1} K_{2} K_{3}\right)^{-3 / 2} .
\end{aligned}
$$

The heat flow in (2) is equal to 1 .

In order to describe the thermoelastic deformation we take the elastostatic equation with bulk thermoelastic forces at the right side of the equation : $\frac{1}{2} c_{i j k l} \frac{\partial}{\partial x_{j}}\left(\frac{\partial u_{k}}{\partial x_{l}}+\frac{\partial u_{l}}{\partial x_{k}}\right)=\beta_{i j} \frac{\partial T}{\partial x_{j}}, \quad i, j, k, l=1,2,3$.

Here $x_{i}$ are the coordinates, $u_{i}$ are the displacement vector components, $c_{i j k l}$ are the elastic coefficients, $\beta_{i j}=c_{i j k l} \alpha_{k l}$ is the thermoelastic tensor and $\alpha_{k l}$ is the thermal expansion tensor.

The system of equations (3) is very difficult to solve analytically and we shall make several simplifying assumptions. Firstly we assume that thermoelastic anisotropy is defined mainly by the thermal anisotropy and less by the elastic anisotropy. That is why in the left side of (3) we reduce the anisotropic coefficients $c_{i j k l}$ to two effective isotropic values $\lambda$ and $\mu$ calculated by Fedorov's method of difference minimization (4). In the right side of (3) such a reduction is not necessary and (3) becomes :

$$
\mu \frac{\partial^{2} u_{i}}{\partial x_{j}^{2}}+(\lambda+\mu) \frac{\partial^{2} u_{j}}{\partial x_{i} \partial x_{j}}=\beta_{i j} \frac{\partial T}{\partial x_{j}}
$$

Even in this simpler form the system of equations (4) is difficult to solve analytically. In order to obtain some general although approximate solution we assume that the shear thermoelastic deformations are more homogeneous than the longitudinal thermal expansion along the main axes. So ignoring all derivatives of the shear deformations we obtain the equations :

$$
(\lambda+2 \mu) \frac{\partial^{2} u_{i}}{\partial x_{i}^{2}}=\beta_{i} \frac{\partial T}{\partial x_{i}} .
$$

Here $\beta_{i}=c_{i j} \alpha_{j}$ because all non-diagonal components of the tensor $\alpha_{i j}$ are zero. The system of equations (5) is easily integrated together with (2) resulting in the following approximate solution for the $i$-th displacement component :

$$
\begin{aligned}
u_{i}=[ & {\left[\beta_{i} /(\lambda+2 \mu)\right]\left(K_{1} K_{2} K_{3}\right)^{-3 / 2} \times } \\
\times & \times\left[\left(x_{1}^{2} / K_{1}\right)+\left(x_{2}^{2} / K_{2}\right)+\left(x_{3}^{2} / K_{3}\right)\right]^{-1 / 2}
\end{aligned}
$$

The surface deformation topography for an $i$-th cut crystal is described by the formula $u_{i}\left(x_{i}=0\right)$. If the crystal is not cut along the main axes, the laboratory and crystallographic coordinate systems differ from one another by a constant angle of rotation and the vector translation relations must be used to obtain the right results.

\section{Results and discussions.}

We have examined some transparent materials such as quartz $X, Y, Z$ and $\mathrm{AT}$ cuts and some glasses. In figure 2 the pictures of the Newton fringes for a glass plate $-1 \mathrm{~cm}$ thick are shown without and in presence of the surface deformation. In every point of the picture one can measure accurately the relative phase difference and thus define the amplitude of the surface 
deformation at this point. The accuracy of measurement is limited only by our possibility to enlarge linearly the photograph picture and define precisely the centre of the zero interference order. Without special efforts we have achieved an accuracy of about $10^{-8} \mathrm{~m}$.

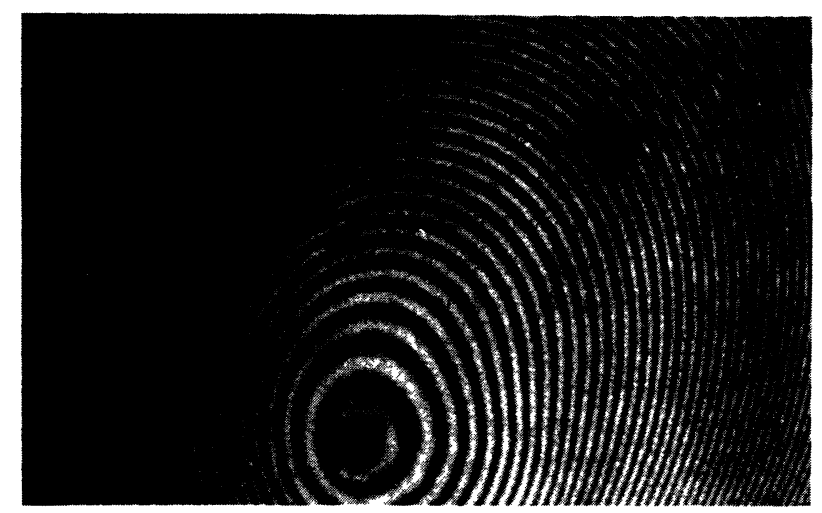

a)

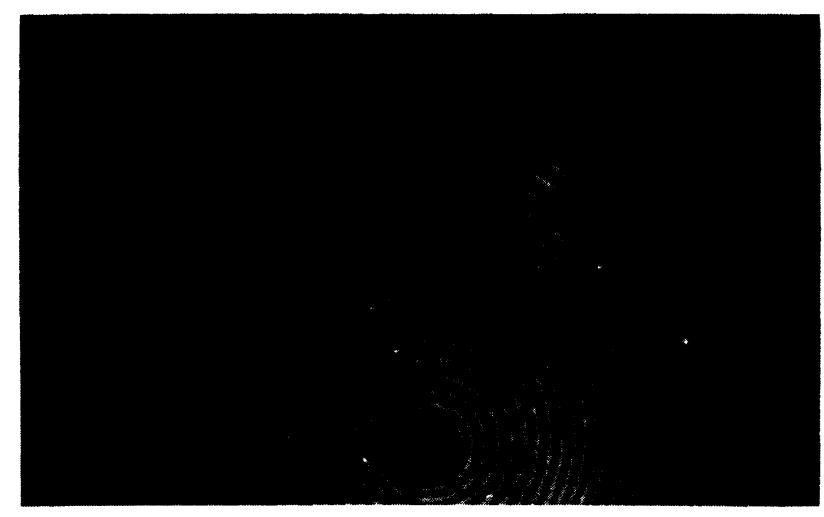

b)

Fig. 2. - Newton fringes with a glass sample. a) Without heating. b) With heating.

In figure 3 the experimental (dashed lines) and theoretical (continuous lines) profiles of the surface deformations for a $X$-cut quartz in the planes $X Y$ and $X Z$ are compared. The quartz sample was a cube with edges $3 \mathrm{~cm}$ in length, cut along the main crystallographic axes. The experimental curves are obtained by evaluating the phase shifts in figure 2 . The phase shifts due to temperature variations of the index of refraction within the material or the air heating close to the heated surface are not taken into account because they are much smaller than the phase shifts due to the surface deformation. The theoretical curves are calculated from (6) where $\lambda=0.82 \times 10^{10} \mathrm{~N} / \mathrm{m}^{2}$ and $\mu=4.72 \times 10^{10} \mathrm{~N} / \mathrm{m}^{2}$ are the values of the effective elastic coefficients of quartz calculated after Fedorov (4). The asymmetry of the profiles in the planes $X Y$ and $X Z$ is 0.85 for the experiment and 0.77 for the theory. The slopes of the theoretical curves also differ a little from the experimental ones which is probably due to the neglected elastic anisotropy.

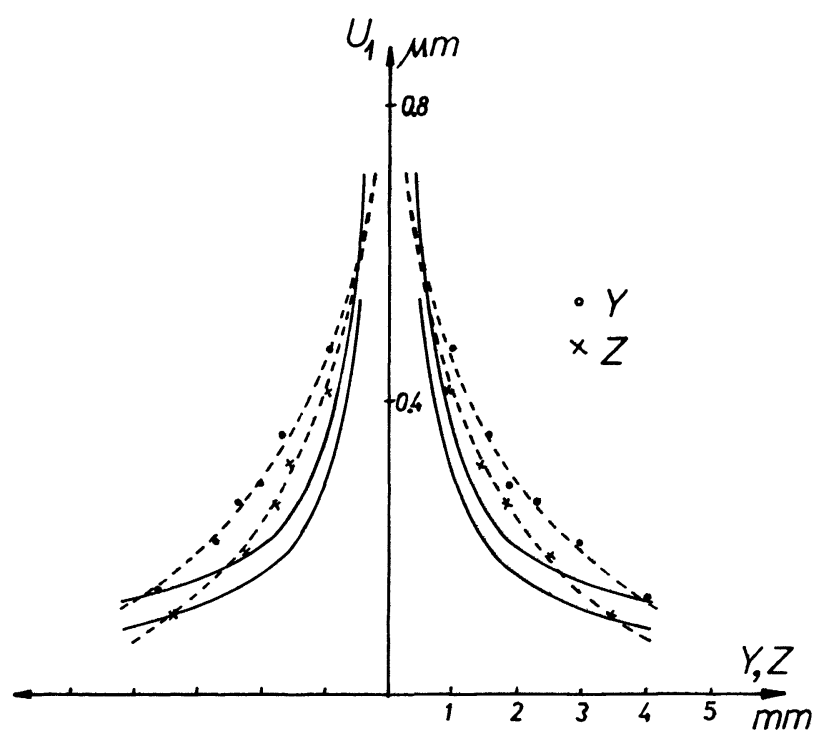

Fig. 3. - Experimental and theoretical (dashed and continuous lines respectively) profiles of the surface deformations for a $X$-cut quartz in the planes $X Y$ and $X Z$.

From (6) it is clear that the amplitude of the surface deformation is proportional to the coefficient of thermal expansion and the steepness of the slope is inversely proportional to the heat flow coefficient $K$ because a smaller $K$ ensures a greater temperature gradient. Thus for quartz $\alpha_{1}=\alpha_{2}=13.4 \times 10^{-6} \mathrm{~K}^{-1} ; \alpha_{3}=7.8 \times$ $10^{-6} \mathrm{~K}^{-1}, K_{1}=K_{2}=3.22 \times 10^{-5} \mathrm{~W} / \mathrm{m} . \mathrm{K}, K_{3}=$ $5.35 \times 10^{-5} \mathrm{~W} / \mathrm{m} . \mathrm{K}$ we have a small amplitude. For glass $\alpha=8.5 \times 10^{-6} \mathrm{~K}^{-1}$ and $K=0.74 \times$ $10^{-5} \mathrm{~W} / \mathrm{m} . \mathrm{K}$ and the amplitude is greater as shown in figure 4 .

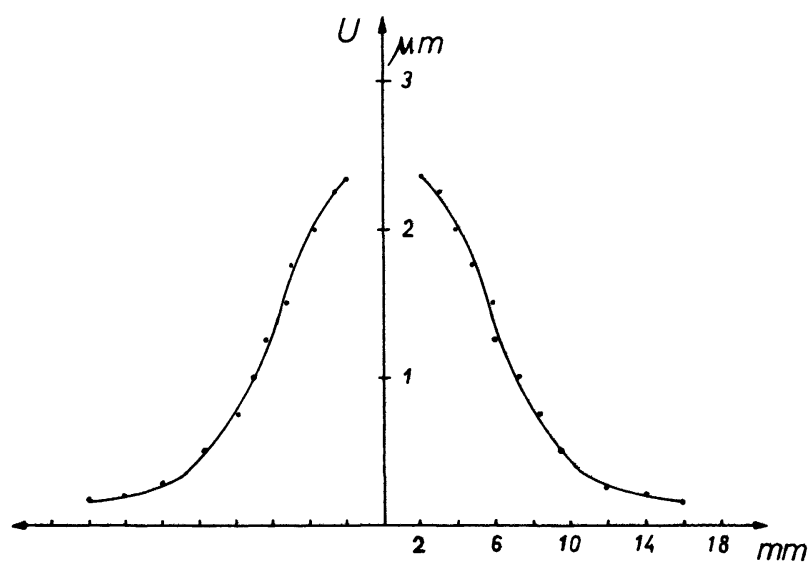

Fig. 4. - Experimental and theoretical profile (the points and the continuous line respectively) of the surface deformations of a glass sample.

We could also observe that the change of Newton fringes with time is very irregular but for exact quantitative results a fast camera should be used to obtain the time evolution of the surface deformation. The information obtained by measuring the time for reaching 
the regime of stationary surface deformation and the time of thermal relaxation will be useful for the study of the dynamical regime of surface acoustic wave thermal generation.

In figure 5 a drawing of the view of the surface deformation of an AT-cut quartz is given. One can notice the

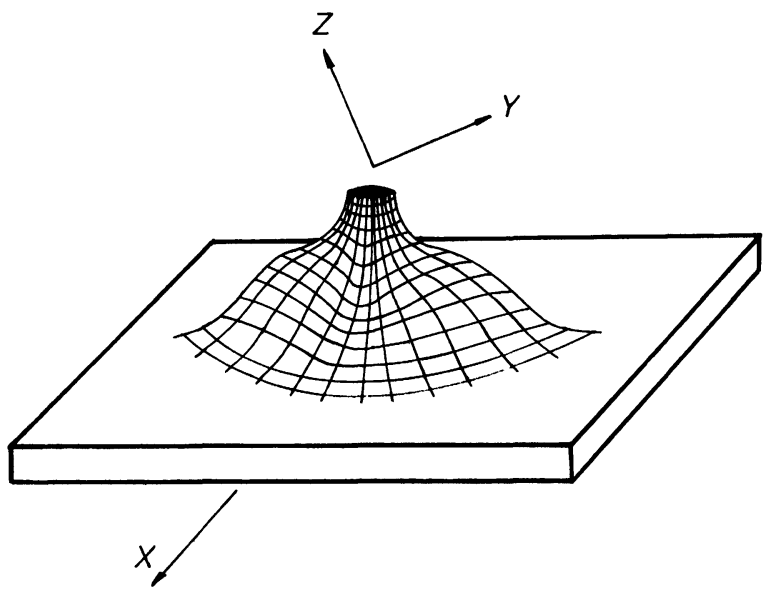

Fig. 5. - A view of the surface deformation of an AT-cut quartz sample. different kind of slopes in different cross sections, describing the thermoelastic anisotropy. Evidently if some complex structure region of heterogeneity or defects are present under the surface of an arbitrary sample they will be visualized in the bulge shape.

\section{Conclusions.}

A method is presented for an accurate experimental measurement and a theoretical evaluation of the topography of the surface thermoelastic deformations induced by a CW laser focused on the surface of a solid. Some isotropic and anisotropic materials have been examined experimentally and theoretically. The information that one can obtain by calculation or experiment is applicable in the following cases : visualization of the thermoelastic properties of anisotropic materials, visualization of the time evolution of the surface deformation and defining the thermal relaxation, finding out optimal cuts and materials for the thermal excitation of surface acoustic waves by a laser, realization of photodisplacement microscopy.
[1] Ash, E. A., Dieulesaint, E., Rakouth, H., Electron. Lett. 16, 12 (1980) 470.

[2] Ameri, S., Ash, E. A., Neuman, V., Petts, C. R., Electron. Lett. 17, 10 (1981) 337.
[3] Cachier, G., J. Acoust. Soc. Am. 49 (1971) 974.

[4] Fedorov, F. I., Theory of elastic waves in crystals (in russian), Moscow 1965, p. 189-195. 